\title{
Artigo
}

REsumo
No campo da investigação
psicanalítica, o relato de
casos clínicos é entendido
como uma ferramenta para a
elaboração teórica das
experiências psicanalíticas.
Pretende-se, neste trabalho,
apresentar os fundamentos
teóricos e discutir o uso do
relato de casos como um
método de investigação e
elaboração psicanalítica a
partir de uma pesquisa na
qual foram comparados os
relatos de atendimentos
realizados em dois tipos de
dispositivos clinicos: o
atendimento institucional e o
atendimento individual. A
partir das reflexões deste
trabalho, conclui-se que os
relatos de caso são parte
integrante do próprio
atendimento, e podem
constituir, tanto nos
individuais como nos
institucionais, material para
a apreensão diagnóstica do
caso, tendo em vista que em
ambos a transferência, em
diferentes manifestações, está
presente.
Descritores: psicanálise-
instituição; psicose infantil;
métodos de pesquisa;
psicanálise-metodologia;
psicanálise da criança

\section{O RELATO DE CASOS CLÍNICOS EM PSICANÁLISE: UM ESTUDO COMPARATIVO}

\author{
Sandra Aparecida Serra $Z_{\text {anetti }}$ \\ Maria Cristina Machado Kupfer
}

\section{O Lugar do Relato de Caso na Pesquisa em Psicanálise}<smiles>c1cc2cc(c1)C2</smiles>
lar seu trabalho de construção teórica aos moldes da ciência de seu tempo. Segundo Lowenkron (2004), Freud utilizava o método de submeter o material da experiência às idéias abstratas para buscar o entendimento dos fenômenos e para atender ao rigor científico; as idéias abstratas, a especulação, poderiam ser descartadas posteriormente ou não, na medida em que se apresentavam como importantes ou ineficazes para a elaboração da experiên-

Mestranda em Psicologia Clínica na Universidade de São Paulo.

- Professora Livre-Docente do Instituto de Psicologia da Universidade de São Paulo. 


\section{Artigo}

cia. Pode-se acompanhar essa construção metodológica em Os Instintos e suas Vicissitudes, em que Freud (1915/1974a) enuncia seu modo de fazer pesquisa teórica.

A direção da pesquisa psicanalítica é dada pela experiência psicanalítica; desde os primeiros trabalhos de Freud, a clínica forneceu a base e o norte a partir dos quais se construíram os eixos fundamentais da elaboração teórica em psicanálise (Lowenkron, 2004).

Se a experiência fornece as bases da construção teórica, então o relato do caso - um caso único -, ou seja, os desdobramentos de uma análise e seu acompanhamento pelo analista, são um instrumento na construção do método e da pesquisa em psicanálise.

Mas já são bem conhecidas as objeções científicas ao método psicanalítico: segundo Popper (1994), um de seus principais críticos, o material clínico resultante não é padronizável e as formulações teóricas daí resultantes não podem ser refutadas. De outro lado, Figueiredo e Vieira (2002), sugerem que se Popper questionasse Freud sobre como refutá-las, ele teria respondido com um critério de validação diferente do da ciência "ideal": o de uma construção. Ou seja, apesar de os critérios de validação da psicanálise dificilmente serem defensáveis do ponto de vista dos moldes científicos atuais, ela tem algo a propor no que diz respeito à questão da refutação. Para Freud (1937/1974b), “a construção deve conjugar não somente alguns pontos da experiência, mas algo que permita incluir, na elaboração do caso, uma espécie de ponto fixo, que estaria no campo do vivido subjetivo do paciente e que, uma vez incorporado à teorização, permite que ela seja apropriada pelo sujeito com certeza inabalável" (Freud, 1937/1974b, p. 291).

Esta é uma primeira indicação, fornecida por Freud, a respeito da elaboração de um caso: a construção permite a incorporação de um ponto fixo em torno do qual se faz uma teorização do caso.

O debate em torno do rigor do método psicanalítico é longo, mas alguns argumentos permitem a sua sustentação e justificam o uso do caso clínico como um de seus instrumentos.

Para Figueiredo e Vieira (2002) um sujeito vem ao psicanalista porque se encontra diante de um impasse que, absolutamente singular, gera um sofrimento indizível. O analista deve utilizar sua construção do caso para pôr em cena não somente os contornos desse sofrimento indizível, mas também o próprio indizível como vazio interior.

Ao abordar o dualismo "teoria e experiência psicanalítica", Birman (1994) delimita o lugar epistemológico ocupado pela teoria em psicanálise e sua articulação com as operações reguladoras do ato psicanalítico e considera que os impasses do processo psi- 


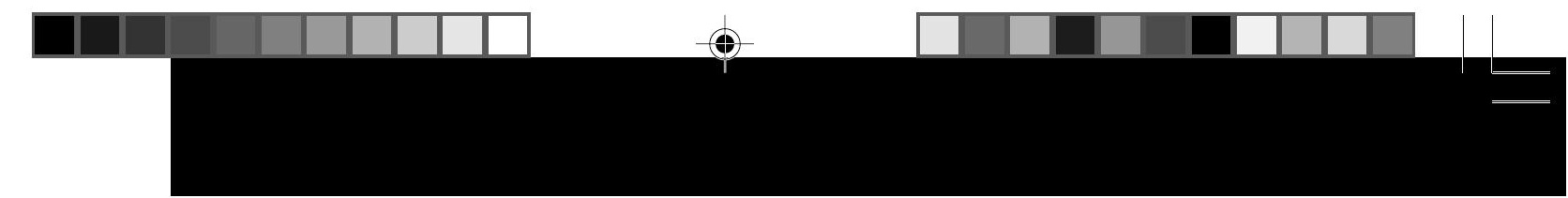

canalítico sempre funcionaram como estímulos que levavam Freud a questionar a consistência da teoria psicanalítica, o que demandava a produção de rupturas e avanços conceituais significativos.

Figueiredo e Vieira (2002) assinalam ainda que há na psicanálise uma relação indissociável entre investigação e tratamento e que, portanto, a pesquisa em psicanálise só pode se configurar e se sustentar na produção de um saber possível sobre as próprias sutilezas de tal relação. Isto porque a psicanálise, segundo estes autores, não se define apenas pelo exercício da investigação de conceitos, o que resultaria em uma "hipertrofia da especulação" (Freud, 1933/ 1976), nem tampouco pela pura terapêutica sem nenhuma formalização conceitual, "o que nos levaria aos equívocos de uma prática intuitiva e pouco rigorosa" (Figueiredo \& Vieira, 2002, p. 26).

Contudo, Figueiredo e Vieira (2002) concluem que os efeitos de verdade passíveis de serem produzidos a partir da aplicação do método de pesquisa só podem ser recolhidos por cada um no particular de sua experiência e, por outro lado, as condições e as premissas para que tais efeitos ocorram devem fazer parte da própria estrutura do método. "Confirma-se, desse modo, uma das premissas fundamentais da psicanálise: o universal que regula sua prática de investigação e tratamento é 'não-todo', ainda que algo de uma universalização do saber deva ser obtido visando à transmissão" (Figueiredo \& Viera, 2002, pp. 26-7).

É na passagem da experiência psicanalítica para elaboração teórica que se pode localizar o método do relato de casos clínicos. O relato do caso é o primeiro passo e ao mesmo tempo o passo fundamental para o encontro da experiência psicanalítica com a elaboração teórica: será por meio de um relato que se terá acesso ao caso e a tudo o que ele puder suscitar em nós.

\section{Fundamentações Teóricas do Método do Relato Clínico}

É no relato clínico que se fundamenta a construção teórica em psicanálise, na medida em que o caso, único, permanece como marca distintiva do método psicanalítico. Para Figueiredo e Vieira (2002), a partir do relato do caso temos um texto que já faz o recorte do analista, com as passagens escolhidas e privilegiadas em determinado momento. "O caso é o produto que se extrai da história, das intervenções do analista na condução do tratamento e do que é decantado de seu relato" (p. 28).

Rudelic-Fernandez (2002) admite que o texto de um caso é como "'palavra plena' na qual trabalha o inconsciente e na qual o 


\section{Artigo}

sujeito é posto em relação com a linguagem do desejo, capaz de suportar a falta, a incompletude, em detrimento da tentação imaginária da identidade e da finitude do sentido" (p. 66).

Para Jerusalinsky (2004), um caso é uma narrativa qualquer, uma novela, até que alguém nos apresente um enigma, uma interrogação. "Alguém que vem nos contar sua vida não é um caso" (p. 16). E a formulação desse enigma ou dessa interrogação é papel fundamental nosso. Para ele, o que justificaria ainda o nome de clínico ou de analista é o fato de que "se possa lidar precisamente com este buraco que, além do mais, é o que faz com que esse caso, que ali se transforma num caso, seja precisamente neste ponto que se torna caso: onde bordejamos esse buraco de ignorância e nos decidimos a lidar com ele" (Jerusalinsky, 2002, p. 16).

Para Nasio (2001), um caso exerce três funções: didática, metafórica e heurística. Ao apresentar um exemplo clínico que mostra os conceitos, transforma o leitor num ator que, pela encenação improvisada de um papel, inicia-se na prática e assimila a teoria. "É essa a função didática do caso: transmitir a psicanálise por intermédio da imagem, ou mais exatamente, por intermédio da disposição em imagens de uma situação clínica que favorece a empatia do leitor e o introduz sutilmente no universo abstrato dos conceitos" (Nasio, 2001, p.12).

Pensando em casos célebres da psicanálise, Nasio (2001) também atribui a função metafórica aos casos, nos quais a observação clínica e o conceito que ela ilustra estão tão intimamente imbricados, que a observação substitui o conceito e se torna metáfora dele. "O sentido inicial de uma idéia tornou-se, pouco a pouco, o próprio sentido do seu exemplo, a tal ponto que basta a simples menção do nome próprio do caso (Joey, irmãs Papin, Dominique etc.) para fazer com que jorre instantaneamente a significação conceitual" (Nasio, 2001, p. 16).

Além disso, o caso pode ultrapassar seu papel de ilustração e de metáfora emblemática, tornando-se, em si mesmo, gerador de conceitos: “Às vezes, a fecundidade demonstrativa de um exemplo clínico é tão frutífera, que vemos proliferarem novas hipóteses que enriquecem e adensam a trama da teoria" (Nasio, 2001, p. 17).

\section{Modos de Construção do Relato}

A pesquisa em foco neste trabalho se baseou em três metodologias de relato de caso, que mantêm entre si uma relação estreita por se originarem na psicanálise ou por se basearem em uma concepção de linguagem que se aproxima da psicanalítica.

A primeira metodologia refere-se à estrutura de construção de um texto teórico em sua articulação com os fatos, conteúdos, história e compreensão do caso clínico Foi proposta por Alfredo Jerusalinsky (2004) baseando-se na noção de tempo lógico apresentada por Lacan (1998) em seu texto $O$ tempo lógico e a asserção de certe- 



\section{Artigo}

não estavam ali. Para Jerusalinsky (2004), este é o ponto fundamental deste método: "o método nos diz, do ponto de vista analítico, por onde começar, e nos diz que é imprescindível que não saibamos onde terminar" (p. 24).

A segunda metodologia nos dirá a respeito da construção literária do texto do relato.

Dana Rudelic-Fernandez (2002), em um volume do Jornal de Psicanálise publicou um artigo intitulado "Linguagem do Caso: modelos e modalidades" no qual apresenta quatro modelos para a narrativa do caso clínico em psicanálise: científico, histórico, literário e hermenêutico. Dentre esses modelos apresentados, foram destacados nesta pesquisa o modelo literário e o modelo hermenêutico, já que, como aponta Frayze-Pereira (2004), esses modelos estão de acordo com a investigação no campo da psicanálise.

Segundo Rudelic-Fernandez (2002), o modelo literário se fundamenta em uma visão literária da história do caso, na qual a imagem da realidade é amplamente determinada por características emprestadas à realidade, tanto no plano do conteúdo quanto no plano da forma. Assim, o relato do caso é neste modelo considerado principalmente como exercício retórico. Ele será analisado através de uma série de figuras retóricas (metáforas, metonímia, sinédoque, paranomásia, etc.) que remetem aos afetos e às suas representações. "As poéticas clássicas consideram toda obra de ficção como obra literária. Entretanto, o simples fato de narrar é ele mesmo gerador da ficção" (p. 62). O relato opera como metáfora, afirmando a semelhança, introduzindo um vínculo causal, cronológico e discursivo entre os acontecimentos esparsos, combinandoos através das semelhanças percebidas. Isto pressupõe que os incidentes percebidos como puramente contingentes sejam rejeitados, pois são não assimiláveis à trama da narrativa. Nesse método, o caso deve ser apresentado como um enigma, à semelhança do que apontou Jerusalinsky (2004).

No modelo hermenêutico, como no modelo literário, o impacto da linguagem sobre a realidade clínica é majorado. Nessa perspectiva, a história clínica é uma re-descrição, uma re-narração da ação que é o tratamento cuja história mesma é modificada pelo próprio fato de ser narrada. Nessa medida, o relato não segue um esquema narrativo dado, não busca superpor a uma verdade canônica uma verdade narrativa. Ele se torna passo a passo uma leitura circunstanciada, pontual, descontínua, desenhando o próprio espaço que ele investe. A particularidade da visão hermenêutica é a de ser ao mesmo tempo uma crítica, uma leitura "desconstrutiva" e uma operação de decifração da história do caso. 
A terceira metodologia é aquela que pode ser extraída da noção freudiana de construção, já mencionada no início deste trabalho. De fato, se a construção é, para Freud, a introdução de um ponto fixo em torno do qual se elabora o caso, pode-se pensar que a idéia de enigma central a ser construído pelo analista é um procedimento que já se encontra de certa maneira no texto freudiano. Essa indicação foi igualmente considerada na elaboração dos relatos de caso da pesquisa em foco.

Assim, os casos foram relatados tendo em vista:

(a) A sua compreensão através da "quebra do estreitamento da extensão simbólica".

(b) A sua apresentação usando o enigma do caso como ponto nodal.

(c) Os modelos literário e hermenêutico de construção do texto;

(d) A noção freudiana de construção.

\section{A Pesquisa Propriamente Dita}

Tendo em vista a comparação de dois tipos diferentes de relato de caso, o primeiro realizado a partir do atendimento individual e o segundo a partir do atendimento institucional, a pesquisa em foco no presente trabalho procedeu à construção e à comparação de textos elaborados a partir das seguintes situações clínicas:

1. Atendimento institucional de A., realizado e relatado pela pesquisadora.

2. Atendimento individual de G., realizado e relatado pela pesquisadora.
3. Atendimento institucional de G., realizado e relatado por profissionais da instituição.

Os relatos de casos foram realizados utilizando a articulação das três metodologias discutidas no início deste trabalho, o que é possível graças ao fato de que as três podem ser consideradas freudianas ou mantêm com a psicanálise uma relação estreita.

Para a realização do estudo, optou-se por utilizar dois tipos de procedimento: num deles, a pesquisadora, diretamente em contato com um caso clínico (G.), através de sessões individuais com uma criança, tinha a possibilidade de comparar o relato de caso construído a partir deste material com o relato de um outro caso clínico institucional (A.), também produzido pela pesquisadora; e no outro procedimento, a pesquisadora teve a possibilidade de novamente comparar o relato de caso clínico individual (G.) com o da mesma criança, mas com material proveniente do seu atendimento institucional, que fora realizado, desta vez, por profissionais da instituição.

As três situações acima referidas foram criadas para tornar possível a consideração da influência do pesquisador em relatos de casos nos quais estava presente em diferentes posições: ora como um dos agentes institucionais, ao lado de outros, ora como analista de uma criança que também era atendida institucionalmente.

Para a análise do material, foram avaliadas as facilidades e dificuldades percebidas nos processos de construção dos relatos de casos pela pesquisa- 


\section{Artigo}

dora decorrentes da influência do tipo de dispositivo clínico (individual ou institucional), bem como a compreensão que foi possível extrair destes relatos. Foi ainda avaliada a influência do tipo de dispositivo clínico sobre a produção do relato, levando-se em conta o lugar da transferência, da escuta e do discurso, bem como os recortes dos textos produzidos pelos vários profissionais da instituição em contato com o caso.

\section{Considerações sobre os Resultados}

A experiência de pesquisa aqui atravessada permitiu a produção de algumas reflexões, dentre as quais foram selecionadas algumas para compor a discussão que se segue.

A construção do relato de um caso atendido em instituição requer uma implicação significativa daquele que se propôs a produzi-lo; sem essa disposição e essa abertura para o caso, não há como tecer e desmembrar um texto ao seu redor.

Essa implicação poderia se tornar mais efetiva caso houvesse a localização de um enigma. Como descrever, porém, em forma de enigma, um caso institucional? De fato, o ponto de partida para essa construção são as premissas estabelecidas por outros, ou seja, as teorias, as interpretações "prontas" do caso. Em resumo, as leituras produzidas pelo Outro institucional, que acabam por chegar àquele que pretende descrever o caso sob forma de algo estabelecido, com pouca possibilidade de in- tervenções ou questionamentos. Chegam quase sempre como um fato estagnado, como letra morta.

O relato de caso institucional ganhou vida no momento em que foi posto em discussão em algumas instâncias institucionais, tais como a reunião clínica e a reunião de estudos. Quando a equipe se envolveu com o pressuposto de Jerusalinsky (2004), o de devolver a polissemia ao significante, ou seja, quando ele foi colocado novamente dentro de um campo no qual os significantes do caso passaram a circular, a produção do caso deixou de se apresentar como um 'relatório de caso'.

O escritor que se propõe a escrever um caso a partir de um material institucional precisará estar disposto a capturar o enigma do caso, muitas vezes perdido entre as teorias estabelecidas sobre ele, descobrir e construir os significantes que o compõem, devolver-lhes a polissemia, proporcionar a extensão da cadeia simbólica do caso e dar-lhe vida durante sua composição.

Já na construção de um relato de caso de um atendimento individual, o enigma do caso - diferentemente do atendimento institucional, no qual ele precisava ser 'caçado' se apresentou de forma muito clara, 'passeando ao nosso redor' e 'nos atravessando' no momento da composição. Entretanto, é interessante acrescentar que o processo de construção deste relato não foi mais simples ou mais fácil que o institucional em decorrência deste aspecto, porque possui as dificuldades de uma construção solitária, diferentemente da construção quase coletiva do relato de caso ins- 


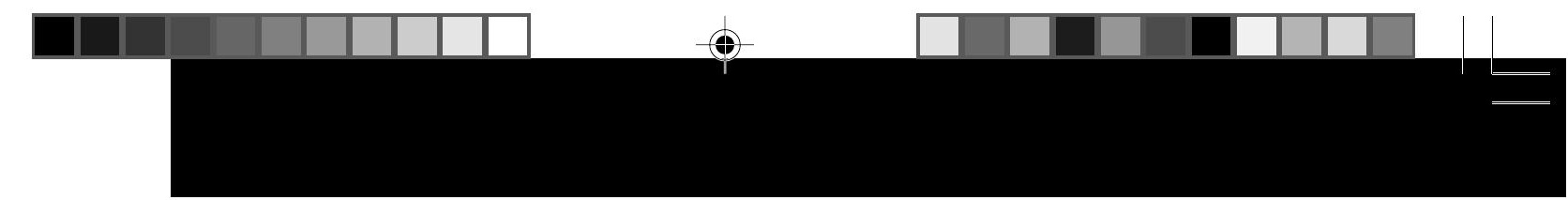

titucional. Ou seja, este é um tipo de processo de construção que não demanda a desconstrução de um enigma, mas sua construção, o encadeamento das idéias, sentimentos e reflexões a respeito do caso, de forma que esteja compatível com os padrões teóricos e técnicos de construção, de acordo com a fundamentação teórica em que se baseiam.

Foi possível, ainda, perceber a influência dos dois tipos de dispositivos clínicos na construção dos relatos de caso. Naturalmente, o relato do atendimento individual baseou-se em um contato mais individualizado, particular com a criança, enquanto o relato do atendimento institucional apoiou-se principalmente no "mundo exterior" da criança, em suas atividades nos grupos de atendimento, em seu modo de se relacionar com as outras crianças etc.

Em um processo de construção de relato de caso institucional, há muitas informações provindas de outros, o que pode contribuir para que este relato não seja um relato de caso, mas um relatório do caso.

Essa observação, por sua vez, sugere que, embora o tipo de material utilizado para a construção do relato, individual ou institucional, tenha uma interferência no processo de elaboração do caso, deve-se introduzir um outro conceito para elucidar essa discussão. É preciso abordar a transferência, como um movimento dentro ou fora do âmbito analítico, que sustenta a prática da construção de relato de caso e proporciona um saber para esse caso. É também no âmbito da transferência que deve ser discutida a possibilidade de construção do diagnóstico do caso a partir dos relatos de casos atendidos individual e institucionalmente.

\section{A Transferência no Relato de Caso}

Segundo Bernardino (2004), Lacan, a partir da importância do inconsciente e da transferência nos tratamentos, define o diagnóstico, em psicanálise, a partir da relação transferencial que aí se estabelece, da posição em que o paciente se coloca e na qual coloca o Outro, denominando este diagnóstico de estrutural. Este Outro, segundo Bernardino (2004), refere-se a um "conceito que define tanto a linguagem, a cultura, as leis, quanto o semelhante (pequeno outro) da espécie, quando representa esta função, ao introduzir o sujeito neste campo" (p. 21).

Pode-se realizar um diagnóstico estrutural de um paciente (e de seus pais) cuja transferência se estabelece com o Outro institucional?

Para levar adiante essa discussão, deve-se estabelecer uma dis- 


\section{Artigo}

tinção entre o conceito de transferência num ambiente de análise e em um ambiente outro qualquer, fora do contexto de análise.

Segundo Laplanche e Pontalis (2004), o conceito de transferência "designa em psicanálise o processo pelo qual os desejos inconscientes se atualizam sobre determinados objetos no quadro de certo tipo de relação estabelecida com eles e, eminentemente, no quadro da relação analítica. Trata-se aqui de uma repetição de protótipos infantis vividos com um sentimento de atualidade acentuada" (p. 514).

Para Monteiro (2002), “a noção de transferência vem revelar a complexidade do encontro entre dois sujeitos, pois nele o sujeito atualiza a realidade de seu inconsciente" (p. 14). Há neste fenômeno a revelação de um sujeito marcado pela falta, quando este se endereça a outro, pois "supõe neste outro o saber sobre seu desejo, sobre isto que lhe falta" (p. 14). No entanto, conforme aponta Nali (2002), "quando se trabalha em psicanálise num contexto outro, que não o consultório privado, algumas particularidades se fazem presentes, principalmente no que diz respeito ao fenômeno transferencial" (pp. 32-3, grifos nossos).

Deste modo, para Dutra (2005), só seria possivel uma apreensão diagnóstica estrutural do caso, através da transferência, no contexto de uma análise. Isto porque, tal como aponta Laplanche e Pontalis (2004), "a transferência é classicamente reconhecida como o terreno em que se dá a problemática de um tratamento psicanalítico, pois são a sua instalação, as suas modalidades, a sua interpretação e a sua resolução que caracterizam este" (p. 514). O diagnóstico psicanalítico, para Dutra (2005), é um dos meios de orientar um tratamento e é na transferência, no desenrolar do tratamento, que este se constitui. Principalmente quando se trata de uma análise de crianças, pois, para estabelecer o diagnóstico na clínica com crianças, os desdobramentos do espaço e do tempo são fundamentais. Segundo esta autora, assim como o inconsciente se revela na repetição, o analista também precisa dela para confirmar sua leitura. Deste modo, portanto, para esta autora, a rigor, trata-se no diagnóstico de poder situar a posição do sujeito na constituição de sua fantasia fundamental. "Qualquer que seja sua temporalidade: pretérita, no caso do adulto, ou gerúndia, no caso da criança” (p. 7). Portanto, conclui esta autora, é impreciso falar em diagnóstico fora do contexto de uma análise: "um diagnóstico no sentido usual não se dá, não se sustenta nessa circunstância" (p. 7).

Da mesma maneira, poder-se-ia pensar que numa instituição as condições necessárias para apreensão diagnóstica estrutural de um caso não estão presentes, pois este só acontece numa relação de transferência num processo de atendimento clínico. 
Outra autora, Nali (2002), também está de acordo com este pressuposto. Para ela, a teoria psicanalítica possui um conjunto de conceitos que são articulados entre si, formulados por um único dispositivo: "a situação analítica, ou seja, um campo privilegiado que possibilita a emergência das chamadas formações do inconsciente do paciente diante do outro, isto é, do sujeito suposto saber, através do qual surge o seu enigma" (p. 37).

Assim, não haveria como pensar o diagnóstico estrutural e a transferência no âmbito institucional, o que cria uma dificuldade em considerar como psicanalítico o atendimento ali realizado. Esse impasse poderá, porém, ser ultrapassado caso se admitam, com Filloux (2002), diferentes modos de apresentação da transferência. Segundo essa autora, pode-se falar de laços transferenciais, entendidos como fenômenos que se manifestam fora do ambiente analítico; por exemplo, na relação que se estabelece entre alunos e professores. Nesses casos, a autora se refere a fenomenos transferenciais, diferentes do que se manifesta na clínica psicanalítica, na qual o que está em jogo é a neurose de transferência que vem substituir a neurose clínica (neurose infantil). Baseando-se em Laplanche e Pontalis, Filloux (2002) entende que os fenômenos transferenciais se referem a equivalentes simbólicos da repetição de experiências do passado, e não a repetições literais. O que quer dizer que "não se poderia ler, decifrar diretamente o sentido dessas manifestações transferenciais porque não há transparência” (pp. 44-5). 


\section{Artigo}

Qual poderia ser, então, o tipo de transferência que se estabelece num âmbito institucional? Nali (2002) assegura que "há transferência do paciente em relação a algum membro da equipe (ou vários) na medida em que retomarmos a idéia de suposto saber, pois havendo em algum lugar o sujeito suposto saber, há transferência” (p. 38). Ou seja, a autora se refere aqui ao fenômeno transferencial que ocorre fora de um contexto de análise. E, deste modo, continua a autora: "evidentemente, temos que considerar que a transferência com um membro da equipe se diferencia da transferência da situação analítica, uma vez que esta tem aí um estatuto próprio” (p. 38).

Justamente, existe, em algumas instituições que abordam a psicose e a instituição na qual se realizou esta pesquisa é uma delas - um profissional que estabelece uma relação mais próxima e sistemática com o caso, responsabilizando-se por ele. Tratase do "profissional de referência do caso". Este profissional escuta regularmente os pais da criança, e algumas vezes na presença da criança. Pode-se afirmar que o tipo de transferência que se estabelece com este profissional aproxima-se daquele que se instala em um atendimento individual, embora não se trate da neurose de transferência classicamente descrita por Freud (1912/1974c). São fenômenos transferenciais, nas palavras de Filloux (2002).

Nesse contexto, pode haver, então, manejos de uma transferência que efetivamente se instala. Portanto, se um relato de caso institucional estiver baseado na relação do profissio- nal de referência, será possível localizar a emergência de fenômenos transferenciais dirigidos à figura do profissional de referência, a partir dos quais uma hipótese diagnóstica será construída.

\section{Supervisão e Narração}

Pode-se ainda propor uma outra discussão a partir da pesquisa em foco. Trata-se de refletir sobre o lugar da supervisão e da narração no relato de um caso clínico.

Em relação a aquilo que a supervisão pode fazer pelo "treinando", Carvalho (2004) destaca: (a) agir de forma que o paciente consiga explorar o próprio comportamento e compreender suas motivações; (b) adquirir a competência de avaliar a tendência do paciente de utilizar soluções automáticas ante situações conflituosas; (c) buscar o passado do paciente sem utilizar questionários; (d) manter-se na postura de "neutralidade técnica"; e (e) ensejar que o paciente alcance qualidade e abrangência na compreensão interna (insight).

Estes aspectos, que podem ser chamados de técnicos de uma supervisão, orientam o "treinando" em relação à postura que deve adotar diante de seu paciente. No presente trabalho, considerou-se, contudo, outro aspecto, também referente ao processo de supervisão; ao narrar um caso, o analista relata ao supervisor aquilo que o paciente fez, suscitou, provocou nele, numa relação de transferência que pretende, através da narração, debruçar-se nos enigmas que compõem o caso e gerar uma com- 
preensão que auxilie na direção do tratamento. Ou seja, faz o mesmo que um relato de caso propõe.

Assim, foi possível perceber que nestes dois processos, o de supervisão e o de construção de relato de caso, há algo que permeia ambos e os torna semelhantes: há um endereçamento do discurso, em forma de narração, a um outro/Outro, em quem se supõe um saber sobre o caso, gerado pelo "simples" processo de narrar. Ambas são práticas que se baseiam na palavra, na linguagem, e são com isso parceiras do próprio processo analítico.

Disto, ainda se pode deduzir a importância de narrar um caso para a condução de um tratamento e, assim, identificar a narração deste caso como parte integrante e essencial do tratamento. Isto porque, diferentemente, por exemplo, de uma prática médica de relatar um caso a um outro médico, esta é parte integrante do processo porque produz efeitos: é necessário que o analista narre um caso, seja a um supervisor ou escrevendo um relato de caso, para que ele possa voltar ao caso e ouvi-lo de um outro lugar. Caso contrário, ele poderá ficar preso nos enlaces do sintoma, principalmente quando se trata da psicose, repetindo um posicionamento provocado por esta captura e pouco poderá fazer pelo paciente. LaznikPenot (1989) relata, por exemplo, o ocorrido em uma instituição de atendimento de crianças psicóticas: o status e o diploma não tiveram o poder de impedir que seus profissionais se livrassem das malhas da repetição que uma criança psicótica pode induzir em seus cuidadores. Foi somente por meio da discussão em equipe e da narração dirigida ao supervisor que os profissionais puderam desvencilhar-se dessa captura.

Pode-se afirmar que a maior contribuição deste trabalho relaciona-se à reflexão em torno do atendimento clínico institucional e suas possibilidades comparadas às de um atendimento individual. A partir das reflexões deste trabalho, conclui-se que caberá aos profissionais de uma instituição cuidar para que o acompanhamento de um caso institucional seja tão sistemático quanto o acompanhamento particular de um atendimento individual. $\mathrm{O}$ trabalho institucional exige um compromisso destes profissionais com o caso de tal modo que este profissional não se perca nos significantes do caso, não seja capturado pelo sintoma do paciente, e esteja a certa distância que a supervisão e a narração permitem manter para tornar possível a decifração do enigma do caso. Em outras palavras, conclui-se que o estudo e o relato de um caso atendido institucionalmente podem se realizar e produzir efeitos semelhantes a aqueles que se alcançam quando se relata um caso acompanhado em um atendimento individual.

Finalmente, este trabalho também possibilitou o acesso a questões relevantes relacionadas à importância da transferência no campo da pesquisa em psicanálise e no trabalho institucional para a construção de relatos de caso, discussão que se buscou em certa medida desenvolver, mas que poderá ser também um ponto de partida para futuros trabalhos. 


\section{Artigo}

\section{Abstract}

THE REPORT OF CLINICAL CASES IN PSYCHOANALYSIS: A COMPARATIVE STUDY

In the field of psychoanalytical investigation, the report of clinical cases is understood as a tool for theoretical elaboration of psychoanalytical experiences. In this work we intend to present the theoretical basis and to discuss the use of case reports as a method of psychoanalytical investigation and elaboration based on a research in which

reports of sessions in two kinds of clinical devices were compared: the institutional session and the individual session. From reflections on this work we conclude that case reports are an integrating part of the session and can become substance for the diagnostic apprehension of the case both in the individual and in the institutional session, for in both transference, in different manifestations, is present.

Index terms: psychoanalysis-institution; infant psychosis; research methods; psychoanalysismethodology; child psychoanalysis

\section{Resumen}

EL RELATO DE CASOS CLÍNICOS EN PSICOANÁLISIS: UN ESTUDIO COMPARATIVO

En el campo de la investigación psicoanalitica, el relato de casos clínicos puede ser una importante berramienta para la elaboración teórica de las experiências psicoanaliticas. En este escrito se presentan los fundamentos teóricos que permiten discutir la utilización del relato de casos como um método de investigación y elaboración psicoanalítica. Eso se plantea desde una investigación en la que se compararon los relatos de atendimientos realizados en dos clases de dispositivos clínicos: individual e institucional. Se concluye que los relatos de caso forman parte del tratamiento, y aportan, tanto en los individuales como en los institucionales, material para la construcción del diagnóstico del caso, ya que en los dos dispositivos la transferéncia está presente.

Palabras clave: psicoanálisis-institución; psicosis infantil; métodos de investigación; psicoanálisis-metodología; psicoanálisis de niños 


\section{Artigo}

Laznik-Penot, M. C. (1989). Seria a criança psicótica uma "carta roubada"? In A. M Souza (Org.), Psicanálise de criança (pp. 4766). Porto Alegre: Artes Médicas.

Lowenkron, T. S. (2004). O objeto da investigação psicanalítica. In F. Herrmann \& T. Lowenkron (Orgs.), Pesquisando com o método psicanalítico (pp. 21-31). São Paulo: Casa do Psicólogo.

Monteiro, A. E. (2002). A transferência e a ação educativa. Estilos da Clinica. Revista sobre a Infância com Problemas. 7 (13), 12-17.

Nali, M. C. (2002). A sutileza da transferência no contexto hospitalar. Estilos da Clinica. Revista sobre a Infância com Problemas. 7 (13), 32-41.

Nasio, J.-D. (2001). O que é um caso? Os grandes casos de psicose. Rio de Janeiro: Jorge Zahar.

Popper, K. R. (1994). Conjecturas e refutações. Brasília: Unb.

Rudelic-Fernadez, D. (2002). Linguagem do caso: modelos e modalidades. Jornal de Psicanálise. São Paulo, 35 (64/65), 5771, dez. 2002.

\section{NOTAS}

1 O estudo focalizado neste artigo é o resultado de uma pesquisa de Iniciação Científica, desenvolvida por Sandra Aparecida Serra Zanetti com a orientação da Profa . Maria Cristina M. Kupfer e apoiada pela FAPESP.

2 O presente trabalho está atrelado ao SubProjeto 2 do Projeto Temático Fapesp: "Efeitos do Tratamento Psicanalítico Institucional sobre a circulação social de crianças e adolescentes psicóticos”, que está sendo realizado na Instituição "Pré-Escola Terapêutica Lugar de Vida”, do IPUSP.

sandraf@pos.ucb.br mckupfer@usp.com.br

Recebido em agosto/2006. Aceito em outubro/2006. 